\title{
EFFECT OF DIFFERENT REPAIR PROTOCOLS ON THE MICRO-SHEAR BOND STRENGTH OF DIFFERENT REPAIR MATERIALS TO INDIRECT COMPOSITE BLOCKS
}

\author{
Mohamed F. Haridy ${ }^{*}$, Hend S. Ahmed ${ }^{* *}$ and Nermeen kamal Hamza***
}

\begin{abstract}
Aim: This study was carried out to investigate the effect of some surface treatment protocols on bond strength of different types of composites to indirect composite blocks at different aging periods

Materials and methods: One hundred and eight discs were obtained from indirect esthetic restorative blocks (Grandio Blocs, VOCO GmbH, Germany) which are designed for Cerec CAD/ CAM system, shade A2, size 14. Three millimeters thick discs were obtained by sectioning the blocks using a low speed isomet saw (Isomet 1000, Buehler Ltd., Lake Bluff, IL, USA). The discs were divided into six groups (18 each) according the surface pre-treatment employed. Group 1: no treatment as control, group 2: roughening with diamond stone, group 3: sandblasting and silica coating. Group 4: etching with phosphoric acid $\% 30$ for one minute, group 5: combination of roughening and etching and group 6: combination of sandblasting and etching. Each group was further subdivided to three subgroups ( 6 each) according to the repair material used either nanohybrid composite, bulk fill composite and organically modified ceramic restorative material (Ormocer). Finally each subgroup was divided into two classes ( 3 each) according to the aging time either 24 hours or 3 months. After surface treatments, Futurabond U (VOCO GmbH, Cuxhaven, Germany) was applied. Before curing, small cylinders were cut from tygon tubes (Norton Performance Plastic Co. Cleveland of USA) with an internal diameter of $0.8 \mathrm{~mm}$ and a height of $1 \mathrm{~mm}$. Five cylinders were mounted on the treated surfaces of each disc $(n=30)$. Finally, the adhesive was light cured for 20 seconds using LED light curing unit. Three repair materials were used in this study. Nano-hybrid resin composite (Grandio) shade A2, regular bulk fill resin composite ( $\mathrm{x}$-tra fil) universal shade and organically modified ceramic restorative material (Ormocer) (Admira Fusion). All materials used were of the same manufacturer (VOCO GmbH, Cuxhaven, Germany). Each material was packed into the cylinder lumen using endodontic plugger and light-cured for 20 seconds using the same light curing unit. For the three-month group, the specimens were stored for three months in
\end{abstract}

\footnotetext{
* Associate Professor of Conservative Dentistry, Faculty of Dentistry, Cairo University and British University in Egypt.

** Lecturer of Conservative Dentistry, Faculty of Dentistry, British University in Egypt

*** Lecturer of Conservative Dentistry, Faculty of Dentistry, October University for Modern Science and Art.
} 
distilled water at room temperature. Using a universal testing machine (Llyod instruments Ltd, fareham UK), the $\mu$-SBS were measured. A wire of $0.2 \mathrm{~mm}$ diameter was looped around the resin composite cylinder. Shear force was applied to each specimen at a cross-head speed of $0.5 \mathrm{~mm} / \mathrm{min}$ until failure occurred.

Results: Regarding 24-hour storage time, One-way ANOVA and post-hoc Tukey's HSD test showed that within Nanohybrid group, Bulk fill group and Ormocer group; Group 6 had the significantly highest $\mu \mathrm{SBS}$. While Regarding three months storage time, One-way ANOVA and post-hoc Tukey's HSD test showed that within Nanohybrid group, Bulk fill group; Group 6 had the significantly highest $\mu$ SBS. Within Ormocer group; Group 5 had the significantly highest $\mu$ SBS. There were no significant differences in $\mu$ SBS detected between the different repair material within each surface treatment group Independent Student-t test revealed that within all study groups, $\mu \mathrm{SBS}$ mean values at 24-hour storage time were significantly higher than those of 3-month ageing time $(\mathrm{P}<0.05)$; except for Group 1 within Bulk Fill group, where $\mu$ SBS mean values did not significantly differ between 24-hour and 3-month ageing time $(\mathrm{P}>0.05)$.

Conclusions: Within the limitation of this invitro study the following conclusions could be drawn: 1- Combination of surface treatment protocols significantly increased the repair bond strength. 2- There was no difference between the three direct resin composite materials on repairing the composite blocks after 24 hours. 3 - The bond strength of the repaired composite blocks after 24 hours storage showed higher micro-shear bond strength than after 3 months aging.

\section{INTRODUCTION}

Recent advances in resin-based composite has led to their use in posterior teeth as it showed many advantages as conservation of remaining tooth structure, adhesion and strengthening of restored tooth, esthetics and ease of repair. Also, the advances in the filler technology has improved the properties of resin-based composite. These developments yielded to the introduction of nanohybrid and nanofilled resin composite. The RBC with nanofillers exhibit filler size ranging from 5-100 nm, yet it still exhibits clinical problems ${ }^{[1,2,3]}$. One of the most precepts in modern dentistry is minimally invasive intervention. Dentists are challenged to avoid unnecessary damage to sound dental tissues and to limit removal to what is strictly necessary.

Identification of the defect in the restoration, and the subsequent decision-making, tends to be limited to visual and tactile examinations; however, the management plan for the restored tooth should be based on risk assessment, including assessment of further caries, structural deterioration, catastrophic failure, and loss of pulp vitality. The recognition of one or more limited defects in a restoration does not necessarily mean that the restoration has suffered irreversible damage and requires immediate replacement ${ }^{[4]}$. Most defects in restorations, other than those caused by sudden impact fracture, develop gradually over extended periods of time, providing the clinician with an opportunity to address the cause of the problem and undertake some form of minimal intervention to correct the defect or defects, thereby extending the life expectancy of the restoration. Minimal intervention treatment may include repair of the defects, especially if the defects are localized and accessible, or simple refurbishment of the restoration if the defects are superficial ${ }^{[5]}$. The main advantage of such approaches to the management of limited defects in restorations is the avoidance of unnecessary removal of intact tooth tissue, leaving restored teeth more able to withstand loading in function and, as a consequence, an improved prognosis. Furthermore, a replacement restoration is always larger than the one replaced, and larger restorations perform less well in clinical service than smaller restorations. Restoration replacement may be inevitable when a restoration is undermined by 
extensive caries or in the presence of cracked cusps adjacent to the existing restoration. Such cracks are not detectable on radiographs and often asymptomatic, even when the crack is quite advanced. In such cases, removing the entire restoration facilitates detection of cracked cusps where the crack typically propagates from the internal line angles of existing restorations ${ }^{[6]}$. So, defects in composite restorations are a common situation for the clinician to decide between repair and replacement.

Repair protocols demonstrated substantial difficulty in establishing a reliable bond to existing aged composite. Despite the presence of the unreacted methacrylate groups after polymerization, the amount of unsaturated double bonds diminishes with aging and reduces the resin adhesion potential. Several surface conditioning methods have been recommended to improve the repair bond strength, such as surface roughening with diamond burs, etching with phosphoric acid or airborne abrasion with aluminum oxide particles or aluminum oxide particles coated with silica ${ }^{[7,8,9]}$. Roughening methods provide surface irregularities, promoting micromechanical interlocking between the substrate surface and the repair resin, but these procedures are further associated with the application of wetting agents such as Silane coupling agents and adhesive resins. The use of adhesive wetting agents promotes chemical adhesion between the repair resin and the substrate ${ }^{[10,11]}$. The surface conditioning based on silica coating followed by salinization and adhesive resin application, called Tribomechanical silica coating which was initially used for conditioning metal alloys of ceramic repair, and it has been tried for repair of conventional resin based composite materials ${ }^{[12,13,14,15]}$. Moreover, resin repair protocols have not been well established for situations where the substrate and the adherend were not of the same kind.

On repairing, the joint between old and new composite may occur by three possible mechanisms, chemical bonding with the organic matrix, chemical bonding with the exposed filler particles and micromechanical retention to the treated surface. The use of one or more of these combinations may depend on the surface substrate to which it is bonded. Although surface roughness promotes mechanical interlocking, bonding agents or Silane primers as intermediate layers improve the surface wetting and chemical bonding with new composite. Previous studies found out that repair of old composite seems to be feasible with the use of self-etching systems, they simplify the adhesion, eliminate the sensitivity and condition both the surrounding tooth surfaces and the resin composite to be repaired at the same procedure ${ }^{[16,17]}$. Till now there is no consensus as the best surface treatment protocol for optimum repair strength of resin composite. Therefore, the aim of our study was carried out to investigate the effect of some surface treatment protocols on bond strength of different types of composites to indirect composite blocks at different aging periods. The null hypothesis of this study was that the various surface treatment protocols would not affect the bond strength of different types of composites to indirect composite blocks at different aging periods.

\section{MATERIALS AND METHODS}

\section{I-Specimen preparation}

One hundred and eight discs were obtained from indirect esthetic restorative blocks (Grandio Blocs, VOCO GmbH, Germany) which are designed for Cerec CAD/ CAM system, shade A2, size 14. Three millimeters thick discs were obtained by sectioning the blocks using a low speed isomet saw (Isomet 1000, Buehler Ltd., Lake Bluff, IL, USA). The surfaces were ground finished with 1200-grit silicon carbide abrasive papers (3M ESPE, St. Paul, MN, USA) under water cooling for surface standardization. ${ }^{[18]}$ They were then ultrasonically cleaned (Vitasonic II, Vita, Bad Säckingen, Germany) in deionized water for $10 \mathrm{~min}$ to remove the loose particles. The discs were embedded in acrylic resin blocks using 
plastic molds with the surfaces to be repaired facing upwards. The discs were artificially aged by storing them in distilled water for 60 days. The water was changed every week to prevent bacterial growth. ${ }^{[19]}$

\section{II-Specimens grouping}

The discs were divided into six groups (18 each) according the surface pre-treatment employed. Group 1: no treatment as control, group 2: roughening with diamond stone, group 3: sandblasting and silica coating. Group 4: etching with phosphoric acid $30 \%$ for one minute, group 5: combination of roughening and etching and group 6: combination of sandblasting and etching. Each group was further subdivided to three subgroups (6 each) according to the repair material used either nanohybrid composite, bulk fill composite and organically modified ceramic restorative material (Ormocer). Finally each subgroup was divided into two classes (3 each) according to the aging time either 24 hours or 3 months.

TABLE (1): Materials specifications, composition, manufacturer and lot numbers:

\begin{tabular}{|c|c|c|c|c|}
\hline Materials & Specification & Composition & Manufacturer & $\begin{array}{c}\text { Lot } \\
\text { number }\end{array}$ \\
\hline Grandio Blocs & $\begin{array}{l}\text { Nano-hybrid com- } \\
\text { posite CAD/CAM } \\
\text { block }\end{array}$ & $\begin{array}{c}86 \% \text { Nanohybrid fillers } \\
14 \% \text { UDMA +DMA }\end{array}$ & $\begin{array}{c}\text { VOCO GmbH, } \\
\text { Cuxhaven, Germany }\end{array}$ & 1904614 \\
\hline $\begin{array}{c}\text { Xtra-fil } \\
\text { (Universal shade) }\end{array}$ & $\begin{array}{l}\text { Multi hybrid } \\
\text { Bulk fill } \\
\text { resin composite }\end{array}$ & $\begin{array}{l}\text { Resin matrix: Bis-GMA, UDMA } \\
\text { and TEGDMA. } \\
\text { Inorganic filler particles ( } 86 \% \mathrm{w} / \mathrm{w}- \\
70.1 \mathrm{vol} \% \text { ): Bariumalumosilicate glass, } \\
\text { fumed silica and ytterbium fluorid. } \\
\text { Photoinitiatior is camphorquinone. }\end{array}$ & $\begin{array}{c}\text { VOCO GmbH, } \\
\text { Cuxhaven, Germany }\end{array}$ & 1421574 \\
\hline $\begin{array}{c}\text { Grandio } \\
\text { (Shade A2) }\end{array}$ & $\begin{array}{l}\text { Nano hybrid resin } \\
\text { composite }\end{array}$ & $\begin{array}{l}\text { Resin matrix: based on dimethacrylates, } \\
\text {.contains Bis-GMA and TEGDMA } \\
\text { Inorganic filler particles: Nano-sized silica } \\
\text {.\% \%iller particles ( } 87 \% \mathrm{w} / \mathrm{w}-71.4 \mathrm{vol} \\
\text { BHT (butyle-hydroxy toluene; inhibitor), } \\
\text { Camphorquinone (photoinitiator) and } \\
\text { (colour pigments (iron oxide }\end{array}$ & $\begin{array}{l}\text { VOCO GmbH, Cux- } \\
\text { haven, Germany }\end{array}$ & 1428322 \\
\hline Admira Fusion & $\begin{array}{l}\text { a Universal nano- } \\
\text { hybrid ORMOCER } \\
\text { restorative material }\end{array}$ & $\begin{array}{l}\text { Resin matrix: Organically modified silicic } \\
\text { acid } \\
\text { Filler: not specified } \\
\text { Filler wt } \% \text { : is } 84 \%\end{array}$ & $\begin{array}{l}\text { VOCO GmbH, } \\
\text { Cuxhaven, } \\
\text { Germany }\end{array}$ & 1802047 \\
\hline Futurabond $\mathbf{U}$ & Universal adhesive & $\begin{array}{l}\text { HEMA, Bis-GMA, HEDMA, acidic adhe- } \\
\text { sive monomer }(*) \text {, urethane dimethacrylate, } \\
\text { catalyst, silica nanoparticles, ethanol }\end{array}$ & $\begin{array}{l}\text { VOCO GmbH, Cux- } \\
\text { haven, Germany }\end{array}$ & 1417136 \\
\hline
\end{tabular}




\section{III-Substrate surface treatments}

All the steps were performed by the same operator following the manufacturers' instructions. According to the assigned groups, the surface treatments were as follows:

Group 1: no surface treatment to act as control.

Group 2: the surface was roughened with diamond stone using a medium grit diamond stone (no. 848, Brassler, Savannah, Georgia, US). The stone was used in 5 strokes with minimal pressure using high speed hand-piece (450000 rpm) with copious amount of coolant. The diamond bur was changed after four preparations to guarantee sharpness and cutting efficiency.

Group 3: sandblasting and silica coating was done using an intraoral air-abrasion device (CoJet; 3M ESPE, Seefeld, Germany) filled with $30 \mu \mathrm{m}$ alumina particles coated with silica (CoJet-Sand, 3 M ESPE AG, Seefeld, Germany) from a distance of approximately $10 \mathrm{~mm}$ at a pressure of 2.5 bars for $10 \mathrm{~s}$.

Group 4: the surface was etched with $30 \%$ phosphoric acid (Scotchbond, 3M ESPE, St. Paul MN, USA) for 60 seconds, rinsed with water spray for 60 seconds and air dried.

Group 5: the surface was roughened with diamond stone as in group 2 and then followed by acid etching for 60 seconds, rinsed with water spray for 60 seconds and air dried.

Group 6: the surface was sandblasted with 30 $\mu \mathrm{m}$ alumina particles coated with silica as in group 3 and then followed by acid etching for 60 seconds, rinsed with water spray for 60 seconds and air dried.

Then, all the discs were ultrasonically cleaned in ethanol for 10 seconds.

\section{IV-Application of the adhesive}

Before application of each repair material, the recommended adhesive of the same manufacturer was applied according to the manufacturer instructions. Futurabond U (VOCO GmbH, Cuxhaven, Germany) was applied on the treated surfaces and scrubbed for 20 seconds with a micro-brush on the substrate surface, air thinned for 10 seconds. Before curing, small cylinders were cut from tygon tubes (Norton Performance Plastic Co. Cleveland of USA) with an internal diameter of $0.8 \mathrm{~mm}$ and a height of $1 \mathrm{~mm}$. Five cylinders were mounted on the treated surfaces of each disc $(n=30)$. Finally, the adhesive was light cured for 20 seconds using LED light curing unit (Elipar S10, 3M ESPE, St Paul, MN, USA) operating in standard mode at light intensity $1200 \mathrm{~mW} / \mathrm{cm}^{2}$. The light intensity was periodically checked with the light meter integrated in the hand piece holder of the curing unit.

\section{V-Application of the repair material}

Three repair materials were used in this study. Nano-hybrid resin composite (Grandio) shade A2, regular bulk fill resin composite (x-tra fil) universal shade and organically modified ceramic restorative material (Ormocer) (Admira Fusion). All materials used were of the same manufacturer (VOCO $\mathrm{GmbH}$, Cuxhaven, Germany).

Each material was packed into the cylinder lumen using endodontic plugger under magnification with 3.5X loupes (Univet, Italy), and a plastic matrix strip was placed over the resin composite and gently pressed flat and light-cured for 20 seconds using the same light curing unit. All specimens were stored for one hour at room temperature before removing the tygon tubes using a blade. In this manner, very small cylinders of resin, approximately 0.8 $\mathrm{mm}$ in diameter and $1 \mathrm{~mm}$ in height, were bonded to the treated surfaces.

\section{VI-Aging of specimens.}

For immediate group, the specimens were stored in distilled water for only $24 \mathrm{~h}$ after resin composite bonding. While for the three-month group, the spec- 
imens were stored for three months in distilled water at room temperature, and the water was changed every week to prevent bacterial growth. ${ }^{[19]}$

\section{VII-Micro-shear bond strength testing}

Using a universal testing machine (Llyod instruments Ltd, fareham UK), the $\mu$-SBS were measured. A wire of $0.2 \mathrm{~mm}$ diameter was looped around the resin composite cylinder and was gently held flush against the direct resin composite-repaired disc interface. The resin-repaired disc interface, the wire loop, and the center of the load cell were aligned as straight as possible to ensure the correct application of the shear force. Shear force was applied to each specimen at a cross-head speed of $0.5 \mathrm{~mm} / \mathrm{min}$ until failure occurred.

Bond strength was calculated according to the formula $R=F / A$, where " $R$ " is the strength (MPa), " $F$ " the load required for rupture of the specimen, and " $A$ " is the interface area of the specimen $\left(\mathrm{mm}^{2}\right)$, $A=\pi r^{2}, r$ is the radius of the specimen, which was checked with a digital caliper before the test.

\section{VIII-Statistical analysis}

Statistical analysis was performed using IBM SPSS Statistics Version 2.0 for Windows. Data was presented as mean and standard deviation (SD). The significance level was set at $\mathrm{P} \leq 0.05$. KolmogorovSmirnov and Shapiro-Wilk tests were used to assess data normality.

Three-way ANOVA was used to evaluate the effect of the experimental variables and their interactions on $\mu$ SBS. Multiple comparisons between different surface treatments and repair materials at each ageing time were performed using One-way ANOVA and post-hoc Tukey's HSD test. Intergroup comparisons regarding ageing time within each surface treatment group were conducted using Independent Student-t test.

\section{RESULTS}

Three-way ANOVA (Table 2) showed that the experimental variables 'surface treatment', 'repair material' and 'ageing time' had a statistically significant effect on $\mu \mathrm{SBS}(\mathrm{P}<0.0001, \mathrm{P}=0.013$ and $\mathrm{P}<0.001$, respectively). While, the interaction between the experimental variables 'surface treatment $\mathrm{x}$ repair material', 'surface treatment $\mathrm{x}$ ageing time', 'repair material $\mathrm{x}$ ageing time' and 'surface treatment $\mathrm{x}$ repair material $\mathrm{x}$ ageing time' showed no significant effect on $\mu \mathrm{SBS}(\mathrm{P}=0.654$, $\mathrm{P}=0.315, \mathrm{P}=0.220$ and $\mathrm{P}=0.222$, respectively).

TABLE (2): Three-way ANOVA for the effect of investigated variables on Microshear bond strength.

\begin{tabular}{|l|c|c|c|c|c|}
\hline \multicolumn{1}{|c|}{ Source } & $\begin{array}{c}\text { Type III Sum } \\
\text { of Squares }\end{array}$ & df & Mean Square & F & Sig. \\
\hline Surface treatment & 1303.032 & 5 & 260.606 & 87.609 & $<0.0001^{*}$ \\
\hline Repair material & 26.215 & 2 & 13.107 & 4.409 & $0.013 *$ \\
\hline Ageing time & 922.834 & 1 & 922.834 & 310.233 & $<0.0001 *$ \\
\hline Surface treatment x Repair material & 23.028 & 10 & 2.303 & 0.774 & 0.654 \\
\hline Surface treatment x Ageing time & 17.681 & 5 & 3.536 & 1.189 & 0.315 \\
\hline Repair material x Ageing time & 9.063 & 2 & 4.531 & 1.523 & 0.220 \\
\hline Surface treatment x Repair material x Ageing time & 39.126 & 10 & 3.913 & 1.315 & 0.222 \\
\hline
\end{tabular}


Regarding 24-hour storage time, One-way ANOVA and post-hoc Tukey's HSD test (Table 3 and Figure 1) showed that within Nanohybrid group, Group 6 had the significantly highest $\mu \mathrm{SBS}$ $(\mathrm{P}<0.05)$, but did not significantly differ from that of Group 5 ( $\mathrm{P}>0.05)$. There were no significant differences observed between Group 3 and Group 5, and between Group 2, Group 3 and Group 4 ( $P>0.05)$. Group 1 yielded the significantly lowest $\mu$ SBS $(\mathrm{P}<0.05)$, but was statistically similar to those of Group 2 and Group $4(\mathrm{P}>0.05)$.

Within Bulk Fill group, Group 6 had the significantly highest $\mu$ SBS $(\mathrm{P}<0.05)$, but had no significant difference from Group 3 and Group 5 (P>0.05). There were no significant differences between Group 2, Group 3 and Group 4, and between Group 1 and Group 4 ( $\mathrm{P}>0.05)$.

Within Ormocer group, Group 6 had the significantly highest $\mu \mathrm{SBS}(\mathrm{P}<0.05)$, but had no significant difference from Group $5(\mathrm{P}>0.05)$. There were no significant differences between Group 2 and Group 3 and between Group 1, Group 2 and Group $4(\mathrm{P}>0.05)$.

On the other side, there were no significant differences in $\mu$ SBS detected between the different repair material within each surface treatment group $(\mathrm{P}>0.05)$.

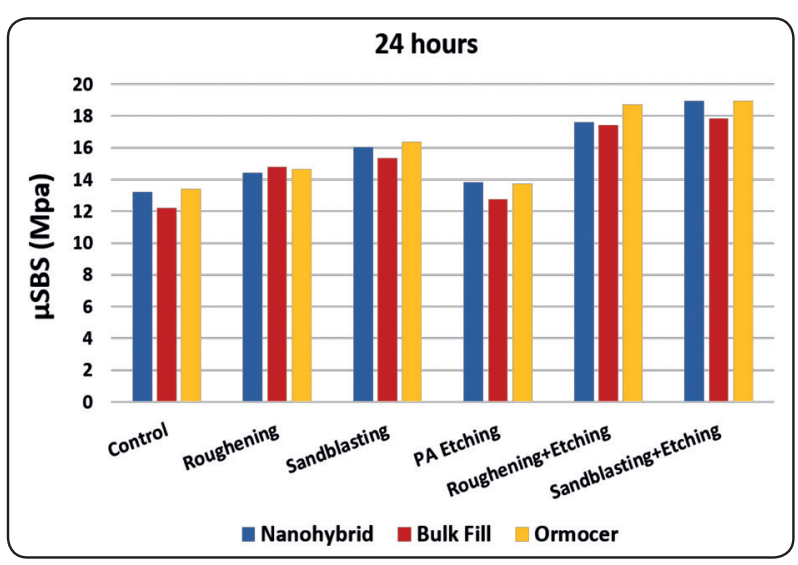

Fig. (1): Bar chart showing the effect of surface treatment and repair material on microshear bond strength $(\mathrm{MPa})$ at 24 hours.

Regarding 3-months ageing time, One-way ANOVA and post-hoc Tukey's HSD test (Table 4 and Figure 2) showed that within Nanohybrid group, Group 6 had the significantly highest $\mu$ SBS $(\mathrm{P}<0.05)$, followed by Group 5. There were no significant differences observed between Group 2 and Group 3 (P>0.05). Group 1 yielded the significantly lowest $\mu \mathrm{SBS}(\mathrm{P}<0.05)$, but was statistically similar to those of Group 2 and Group $4(\mathrm{P}>0.05)$.

TABLE (3): Mean \pm SD and P-value for the effect of surface treatment and repair material on microshear bond strength $(\mathrm{MPa})$ at 24 hours.

\begin{tabular}{|l|c|c|c|c|}
\hline \multicolumn{1}{|c|}{24 hours } & Nanohybrid & Bulk Fill & Ormocer & P-value \\
\hline Control & $13.22 \pm 2.33^{\mathrm{d}}$ & $12.22 \pm 3.15^{\mathrm{c}}$ & $13.41 \pm 1.35^{\mathrm{c}}$ & 0.532 \\
\hline Roughening & $14.41 \pm 1.28^{\mathrm{cd}}$ & $14.80 \pm 10.47^{\mathrm{b}}$ & $14.63 \pm 1.35^{\mathrm{bc}}$ & 0.874 \\
\hline Sandblasting & $16.03 \pm 1.53^{\mathrm{bc}}$ & $15.32 \pm 1.56^{\mathrm{ab}}$ & $16.35 \pm 1.31^{\mathrm{b}}$ & 0.337 \\
\hline Ph Acid Etching & $13.83 \pm 1.19^{\mathrm{cd}}$ & $12.77 \pm 1.02^{\mathrm{bc}}$ & $13.73 \pm 1.64^{\mathrm{c}}$ & 0.192 \\
\hline Roughening+Etching & $17.62 \pm 1.89^{\mathrm{ab}}$ & $17.44 \pm 1.00^{\mathrm{a}}$ & $18.69 \pm 1.14^{\mathrm{a}}$ & 0.143 \\
\hline Sandblasting+Etching & $18.94 \pm 1.28^{\mathrm{a}}$ & $17.84 \pm 1.25^{\mathrm{a}}$ & $18.96 \pm 1.23^{\mathrm{a}}$ & 0.119 \\
\hline P-value & $<0.0001^{*}$ & $<0.0001^{*}$ & $<0.0001^{*}$ & \\
\hline
\end{tabular}

*:P $\leq 0.05 \quad$ Means with identical superscript lowercase letters within the same column are not statistically significantly different at $P \leq 0.05$. 
Within Bulk Fill group, Group 6 had the significantly highest $\mu$ SBS $(\mathrm{P}<0.05)$, but had no significant difference from Group $5(\mathrm{P}>0.05)$. There were no significant differences between Group 1, Group 2, Group 3 and Group 4 (P>0.05).

Within Ormocer group, Group 5 had the significantly highest $\mu \mathrm{SBS} \quad(\mathrm{P}<0.05)$, but had no significant difference from Group 2 Group 3 and Group $6(\mathrm{P}>0.05)$. There were no significant differences between Group 1, Group 2, Group 3 and Group 4 ( $\mathrm{P}>0.05)$.

On the other side, there were no significant differences in $\mu$ SBS between the three repair materials within Group 1, Group 3 and Group 4. While within Group 2, Ormocer presented the significantly highest $\mu$ SBS $(\mathrm{P}<.0 .05)$, but was statistically similar to Nanohybrid ( $>>0.05)$. Bulk Fill had the significantly lowest $\mu \mathrm{SBS} \quad(\mathrm{P}<0.05)$. Within Group 5, Ormocer produced significantly higher $\mu$ SBS value $(\mathrm{P}<.0 .05)$ than those of Nanohybrid and Bulk fill, which were statistically similar $(\mathrm{P}>0.05)$. Within Group 6, Nanohybrid yielded the significantly higher $\mu \mathrm{SBS}$ value $(\mathrm{P}<.0 .05)$. Bulk Fill did not differ significantly from those of Nanohybrid and Ormocer $(\mathrm{P}>0.05)$.

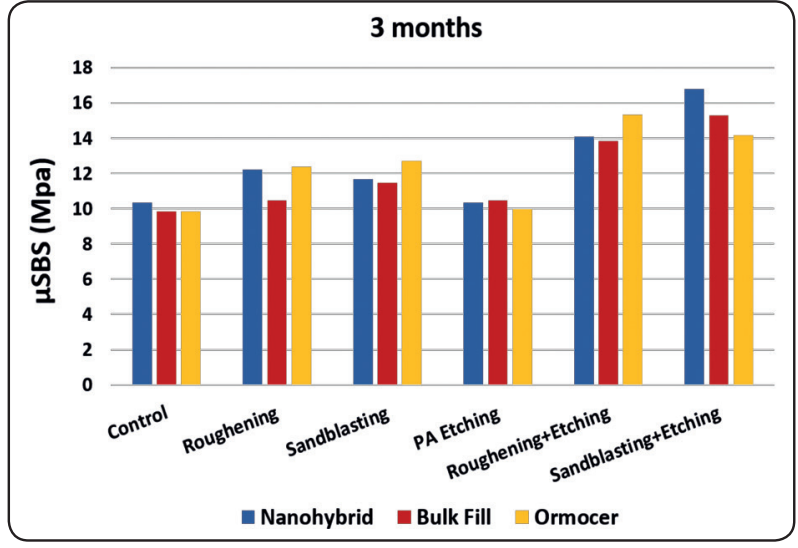

Fig. (2): Bar chart showing the effect of surface treatment and repair material on microshear bond strength $(\mathrm{MPa})$ at 3 months.

Independent Student-t test (Table 5 and Figure 3 ) revealed that within all study groups, $\mu \mathrm{SBS}$ mean values at 24-hour storage time were significantly higher than those of 3-month ageing time $(\mathrm{P}<0.05)$; except for Group 1 within Bulk Fill group, where $\mu$ SBS mean values did not significantly differ between 24-hour and 3-month ageing time $(\mathrm{P}>0.05)$.

TABLE (4): Mean \pm SD and P-value for the effect of surface treatment and repair material on microshear bond strength (MPa) at 3 months.

\begin{tabular}{|l|c|c|c|c|}
\hline \multicolumn{1}{|c|}{3 months } & Nanohybrid & Bulk Fill & Ormocer & P-value \\
\hline Control & $10.33 \pm 1.51^{\mathrm{d}}$ & $9.85 \pm 1.36^{\mathrm{b}}$ & $9.82 \pm 2.48^{\mathrm{b}}$ & 0.806 \\
\hline Roughening & $12.23 \pm 0.93^{\mathrm{cA}}$ & $10.47 \pm 1.30^{\mathrm{bB}}$ & $12.38 \pm 1.08^{\mathrm{abA}}$ & $0.002^{*}$ \\
\hline Sandblasting & $11.66 \pm 1.20^{\mathrm{cd}}$ & $11.46 \pm 1.17^{\mathrm{b}}$ & $12.71 \pm 0.90^{\mathrm{ab}}$ & 0.053 \\
\hline Phosphoric acid etching & $10.33 \pm 1.23^{\mathrm{d}}$ & $10.48 \pm 1.37^{\mathrm{b}}$ & $9.98 \pm 1.21^{\mathrm{b}}$ & 0.692 \\
\hline Roughening+Etching & $14.06 \pm 1.09^{\mathrm{bB}}$ & $13.81 \pm 17.84^{\mathrm{aB}}$ & $15.33 \pm 1.22^{\mathrm{aA}}$ & $0.010^{*}$ \\
\hline Sandblasting+Etching & $16.79 \pm 1.24^{\mathrm{aA}}$ & $15.30 \pm 1.74^{\mathrm{aAB}}$ & $14.18 \pm 1.75^{\mathrm{aB}}$ & $0.008^{*}$ \\
\hline P-value & $<0.0001^{*}$ & $<0.0001^{*}$ & $0.002^{*}$ & \\
\hline
\end{tabular}

*:P $\quad 0.05 \quad$ Means with identical superscript lowercase letters within the same column and uppercase letters within the same row are not statistically significantly different at $P \leq 0.05$ 
TABLE (5): Mean \pm SD and P-value for the effect of ageing time on microshear bond strength (MPa)

\begin{tabular}{|c|c|c|c|c|}
\hline Repair material & Surface treatment & 24 hours & 3 months & P-value \\
\hline \multirow{6}{*}{ Nanohybrid } & Control & $13.22 \pm 2.33$ & $10.33 \pm 1.51$ & $0.008 *$ \\
\hline & Roughening & $14.41 \pm 1.28$ & $12.23 \pm 0.93$ & $0.001 *$ \\
\hline & Sandblasting & $16.03 \pm 1.53$ & $11.66 \pm 1.20$ & $<0.0001 *$ \\
\hline & Phosphoric acid etching & $13.83 \pm 1.19$ & $10.33 \pm 1.23$ & $<0.0001 *$ \\
\hline & Roughening+Etching & $17.62 \pm 1.89$ & $14.06 \pm 1.09$ & $<0.0001 *$ \\
\hline & Sandblasting+Etching & $18.94 \pm 1.28$ & $16.79 \pm 1.24$ & $0.002 *$ \\
\hline \multirow{6}{*}{ Bulk Fill } & Control & $12.22 \pm 3.15$ & $9.85 \pm 1.36$ & 0.063 \\
\hline & Roughening & $14.80 \pm 10.47$ & $10.47 \pm 1.30$ & $<0.0001^{*}$ \\
\hline & Sandblasting & $15.32 \pm 1.56$ & $11.46 \pm 1.17$ & $<0.0001 *$ \\
\hline & Phosphoric acid etching & $12.77 \pm 1.02$ & $10.48 \pm 1.37$ & $0.001 *$ \\
\hline & Roughening+Etching & $17.44 \pm 1.00$ & $13.81 \pm 17.84$ & $<0.0001 *$ \\
\hline & Sandblasting+Etching & $17.84 \pm 1.25$ & $15.30 \pm 1.74$ & $0.003 *$ \\
\hline \multirow{6}{*}{ Ormocer } & Control & $13.41 \pm 1.35$ & $9.82 \pm 2.48$ & $0.002 *$ \\
\hline & Roughening & $14.63 \pm 1.35$ & $12.38 \pm 1.08$ & $0.001 *$ \\
\hline & Sandblasting & $16.35 \pm 1.31$ & $12.71 \pm 0.90$ & $<0.0001 *$ \\
\hline & Phosphoric acid etching & $13.73 \pm 1.64$ & $9.98 \pm 1.21$ & $<0.0001 *$ \\
\hline & Roughening+Etching & $18.69 \pm 1.14$ & $15.33 \pm 1.22$ & $0.012^{*}$ \\
\hline & Sandblasting+Etching & $18.96 \pm 1.23$ & $14.18 \pm 1.75$ & $<0.0001^{*}$ \\
\hline
\end{tabular}

$*: P \leq 0.05$

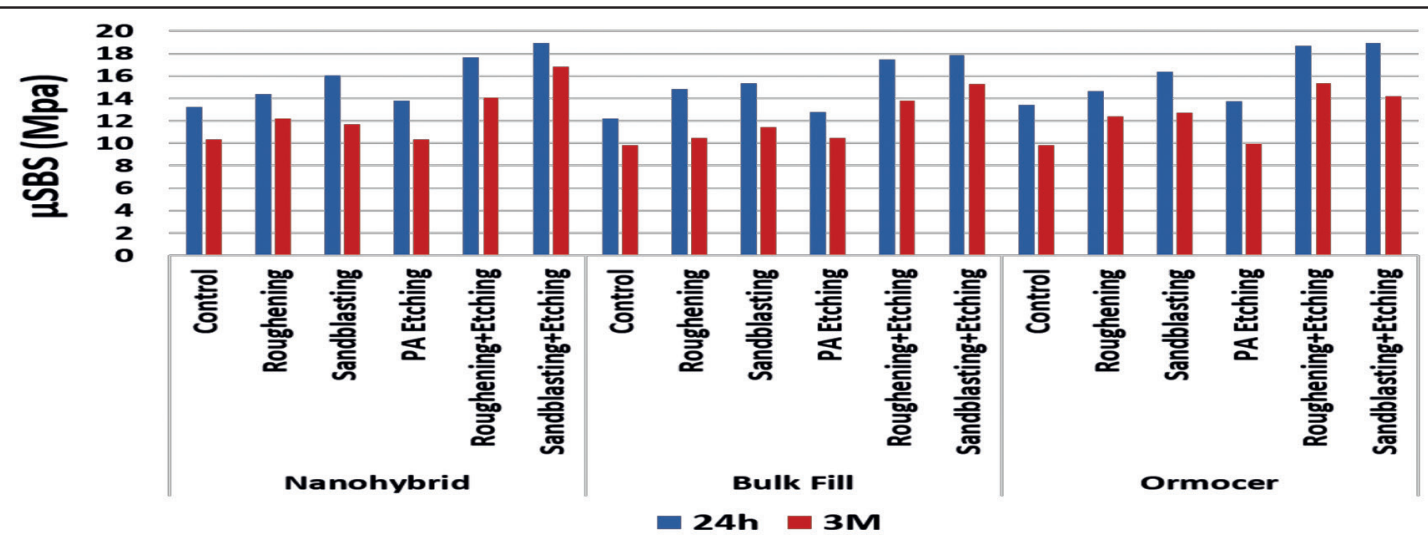

Fig. (3): Bar chart showing the effect of ageing time on micros-hear bond strength (MPa). 


\section{DISCUSSION}

Alternative esthetic restorations have been introduced as digital technologies of CAD/CAM systems. Ceramics and composite have been introduced as indirect restorations using the CAD/CAM systems as promising restorations. Over years indirect composite blocks used for CAD/CAM systems have been improved in relation to their mechanical properties in different ways: alteration in the composition (monomer resins, initiation systems), incorporation of high percentage of filler particles; and polymerization modes (using high temperature and pressure for polymerization). These have improved both tensile and compressive strength, hardness, elastic modulus and wear resistance ${ }^{[20,21,22,23]}$.

It is known that Urethane based and multi-functional Methacrylate monomers form a three-dimensional tetra functional network through radical. During co-polymerization reaction, about $30 \%$ of the total amount of $\mathrm{C}=\mathrm{C}$ bond remain unreacted in the form of large bulk pendant groups. An increase of temperature enhancing radical mobility and polymerization rate, may create a superior crosslinking density and final degree of conversion of dimethacrylate-based monomers. Thus, the indirect composite blocks considered to possess a limited amount of superficial active free radicals available for reaction with new monomer ${ }^{[24,25,26]}$. Therefore, this study aimed to assess the effect of using various surface treatments using different direct composite resin materials on the repair of indirect composite blocks.

The micro-shear bond strength (mSBS) was used to evaluate the composite-to-composite bond strength as it is relatively simple technique, also it is unlike micro-tensile technique sectioning and trimming steps which may introduce early micro-cracking and pre-test failure within the specimens are avoided, therefore, it is more effective and reliable for evaluating bonding efficiency of the adhesive systems. In the current study a bonding agent single bond (Futura bond) was used in all groups prior to adding the direct resin composite. This was done because the reportedly poor wettability properties of the newly composite added necessitate the application of low viscosity bonding agent to enhance the chemical bond to the matrix and exposed fillers, as well as improve micromechanical retention by infiltrating into the micro-irregularities created by the treatment of the surface. Furthermore, a nonpolymerized layer created on the indirect composite blocks by oxygen inhibition which may aid adhesion to the new material. ${ }^{[27,28,29,30]}$ Also, the purpose of surface treatment is to increase the surface energy and/or the surface roughness.

The null hypothesis was rejected, because various surface treatment protocols did affect the bond strength of different types of composites to indirect composite blocks. This study revealed that when composite blocks were mechanically treated using sandblasting followed by acid etching using phosphoric acid for 60 seconds, it showed the highest mSBS with all materials used when evaluated after 24 hours. Followed by the combination of the diamond burs medium grit and acid etching, while there was no statistically significant difference between all other groups (acid etching alone, sand blasting alone and diamond bur alone). Furthermore, the control group showed the lowest repair mSBS. These results were in agreement with Ghazaleh et al as the roughening of the surface of the indirect composite using a combination of surface treatment creates macro-retentive as well as micro-retentive features and this may differentially expose the filler particles which is $87 \%$ in the indirect resin composite blocks used in this study ${ }^{[31,32]}$. Also, on evaluating the repaired resin composite after roughening using sandblasting under SEM it revealed increase in surface roughness in a pattern different than other treatment modalities, also it has been reported that the surface characteristics following sandblasting depends on the micro-structure and composition of the material ${ }^{[33]}$. In nano-hybrid composite resins 
breaking off the clusters occurs when they are subjected to sandblasting. Also, it was found that the smear debris is not removed and this may reduce the bond strength compared to the combination surface treatment technique with acid etching.

According to Susanna et al who found out that under SEM it showed more retentive linear patterns and coarse surface. Roughening by sandblasting remove parts of the soft matrix and create superficial grooves, pits and depressions which gives more micro-retentive features. Moreover, acid etching using the phosphoric acid removed the smear debris that is produced due to grinding procedure and expose the underlying surface and fillers and this results in an increased surface area which can help stress distribution along the interface of the two bonded substrates. Also, it enhanced the surface energy and wettability of the surface promoting adhesion to the repaired material ${ }^{[32]}$. Meanwhile, surface treatment with phosphoric acid should not be used alone in repairing the resin composite blocks as it did not significantly change the morphological pattern and its action is limited to superficial cleaning effect ${ }^{[34]}$. Furthermore, the control group showed the lowest mSBS and this was in agreement with Rinastiti et al which was due to the smooth surface visible by SEM which indicated the importance of surface roughening in improving the repair bond strength of the indirect resin composite block, in which the mechanical interlocking has been determined to be the most important factor in maximizing the repaired bond strength ${ }^{[35]}$.

Clinically aging is a result of exposure of composite material to the oral environment, food and beverages of all kinds and cyclic loading over a long period of service. This aging process will result in leaching of certain components out of the composite resin, water uptake in the resin matrix and along the resin-filler interface and wear of the surface due to loss of resin matrix and filler particles. These changes can alter the composition of the material and will also affect the repair bond strength. Therefore, in the present study aging was done for 3 months in distilled water as to reproduce the hydrolytic degradation in the resin matrix that occur in the oral environment ${ }^{[36,37]}$. After aging, results showed that roughening using the sandblasting followed by acid etching showed the highest mSBS when repaired with bulk fill and nanohybrid resin composite while on using the universal nano-hybrid Ormocer it showed it showed the highest mSBS when roughening with diamond burs followed by acid etching. All other groups showed no statistically significant difference with all three materials. Furthermore, the results of the present study revealed that within all study groups, mSBS mean values at 24 hours storage were significantly higher than those of the 3 months aging time. These results were against those of Farid Elaskary et al, who revealed that water storage did not affect the repair bond strength and this may be due to surface devoid of oxygen inhibited layer, the high-volume percent of filler and the high degree of conversion could be the reason why water storage did not affect the bond strength. Meanwhile the storage period may be a detrimental factor as in their study storage period was for one month, while in the present study it was for 3 months ${ }^{[38]}$. Meanwhile, Fawzy et al attributed drop in the repair bond strength after aging due to the presence of surface degraded layer on the aged composite surface, which was in agreement with the results of the present study ${ }^{[34]}$. The drop of the repair bond strength after aging may be due to the adhesive used in this study containing HEMA which is hydrophilic in nature and encourages water uptake. Hydrolytic instability resulting in water degradation of such adhesive might be expected ${ }^{[39]}$. Thus, it is not unreasonable to presume that with time, the resin composite bond will deteriorate and the repair will be of limited duration in the clinical oral environment.

Furthermore, the composite material may affect the repair bond strength, as in clinical practice the 
type of composite in the immediate repair is usually the same. However, in some situations if the patient already had a composite restoration the information on the substrate type may not be traced. In such situations a different repair composite might be used. Therefore, in the present study three different types of the resin composite were used to evaluate the repair bond strength (Nanohybrid, Bulk fill and Ormocer based composite) with the different surface treatment protocols. Using different materials may affect the repair bond strength as respect to the variation of their filler size, morphology, amount, volume, distribution, chemical composition or variation in the organic matrix according to Cutris et. al ${ }^{[40]}$, and this was in contradiction of the present study, in which the results revealed that the three types of composite resin behaved similarly with the different surface treatment protocols. According to Mutlu özcan et al ${ }^{[41]}$ they found out that nanohybrid resin composite with decreased filler size provide a larger surface area and thus a large filler-matrix interface being more prone to degradation through water uptake and this supported the results of the present study, as the three composite resin materials showed decrease in the repair bond strength with 3 months aging. Also, according to the results of the present study, it was concluded that the ormocer -based-composite showed the same repair bond strength similar to that of the nano-hybrid and bulk fill composite resin after 24 hours and 3 months aging.

Based on the results of this invitro study, for indirect composite blocks; the best surface treatment is the roughening using a combination of sandblasting and acid etching followed by roughening using diamond burs medium grit and acid etching which showed the highest mSBS with all three types of direct resin composite. In terms of bond stability aging for 3 months storage in distilled water tends to reduce the bond strength when compared with that of the 24 hours storage.

\section{CONCLUSION}

Within the limitation of this invitro study the following conclusions could be drawn:

1. Combination of surface treatment protocols significantly increased the repair bond strength

2. There was no difference between the three direct resin composite materials on repairing the composite blocks after 24 hours

3. The bond strength of the repaired composite blocks after 24 hours storage showed higher micro-shear bond strength than after 3 months aging

\section{REFERENCES}

1- Moszner N, Klapdohr S. Nanotechnology for dental composites. Int J Nanotechnol 1:130-156; 2004.

2- Manhart J, Chen H, Hamm G, Hickel R. Review of the clinical survival of direct and indirect restorations in posterior teeth of the permanent dentition. Oper Dent 29:481$508 ; 2004$.

3- Da Rosa Rodolpho PA, Donassollo TA, Cenci MS, Loguércio AD, Moraes RR, Bronkhorst EM, Opdam NJ, Demarco FF. 22-Year clinical evaluation of the performance of two posterior composites with different filler characteristics. Dent Mater 27:955-963;2011.

4- Gordan VV, Riley JL, 3rd, Geraldeli S. Dental PracticeBased Research Network Collaborative Group Repair or replacement of defective restorations by dentists in The Dental Practice-Based Research Network. J Am Dent Assoc.;143(6):593-601; 2012.

5- Gordan VV. Clinical evaluation of replacement of Class $\mathrm{V}$ resin based composite restorations. J Dent.;29(7):485488; 2001.

6- Blum IR, Jagger DC, Wilson NHF. Defective dental restorations: to repair or not to repair? Part 1: direct composite restorations. Dent Update.;38(2):78-80. 82-84; 2011.

7- Swift EJ Jr, LeValley BD, Boyer DB. Evaluation of new methods for composite repair. Dent Mater 8:362-365; 1992.

8- Sau CW, Oh GS, Koh H, Chee CS, Lim CC. Shear bond strength of repaired composite resins using a hybrid composite resin. Oper Dent 24:156-161; 1999. 
9- Pinar Altini, Murat Multuay, Arzu Tezvergil-Mutluay. Repair bond strength of nanohybrid composite resins with a universal adhesive.Acta Bomater Odontol Scand. 4(1): $10-19 ; 2018$

10- Hisamatsu N, Atsuta M, Matsumura H. Effect of silane primers and unfilled resin bonding agents on repair bond strength of a prosthodontic micro-filled composite. J Oral Rehabil 29:644-648; 2002.

11- Costa TRF, Ferreira SQ, Klein-Junior CA, Loguercio AD, Reis A. Durability of surface treatments and intermediate agents used for repair of a polished composite. Oper Dent 35:231-237; 2010.

12- Swift EJ Jr, Cloe BC, Boyer DB. Effect of a silane coupling agent on composite repair strengths. Am J Dent 7:200-202; 1994.

13- Özcan M. The use of chairside silica coating for different dental applications: a clinical report. J Prosthet Dent 87:469-472; 2002.

14- Rodrigues SA Jr, Ferracane JL, Della Bona A. Influence of surface treatments on the bond strength of repaired resin composite restorative materials. Dent Mater 25:442-451; 2009.

15- Sun R, Suansuwan N, Kilpatrick N, Swain M. Characterization of tribochemically assisted bonding of composite resin to porcelain and metal. J Dent 28:441-445; 2000.

16- Lucena-Martin C, Gonzales-Lopez S, Navajas-Rodrigues deMondelo JM.The effect of various surface treatments and bonding agents on the repaired strength of heat-treated composites. J. Prosthet. Dent.; 86: 481-488; 2001.

17- Teixeira EC, Bayne SC, Thompson JY, Ritter AV, Swift EJ. Shear bond strength of self-etching bonding systems in combination with various composites used for repairing aged composites. J. Adhes. Dent.; 7: 159-164; 2005.

18- Ozcan M, Valandro LF, Amaral R, Leite F, Bottino MA. Bond strength durability of a resin composite on a reinforced ceramic using various repair systems. Dent Mater.; 25:1477-83; 2009.

19- Staxrud F, Dahl JE. Role of bonding agents in the repair of composite resin restorations. Eur J Oral Sci.; 119:316-22; 2011.

20- A. Awada and D. Nathanson, "Mechanical properties of resin-ceramic CAD/CAM restorative materials," Journal of Prosthetic Dentistry, vol. 114, no. 4, pp. 587-593, 2015
21- J. Nguyen, V. Migonney, N. D. Ruse, and M. Sadoun, "Resin composite blocks via high-pressure high-temperature polymerization," Dental Materials, vol. 28, no. 5, pp. 529-534, 2012.

22- S.Lin-Gibson, L. Sung, A. M. Forster, H.Hu, Y.Cheng, and N. J. Lin, "Effects of filler type and content on mechanical properties of photopolymerizable composites measured across two-dimensional combinatorial arrays," Acta Biomaterialia, vol. 5, no. 6, pp. 2084-2094, 2009.

23- Neslihan Tinastepe, Elif turkes, Ender Kazazoglu. Comparative approach to analyze the effects of different surface treatments on CAD/CAM resin nanoceramicsresin composite repair bond strength. Biotech and biotechnological equipment. 32 (1); 142-149; 2018.

24- Daronch M, Ruggeberg F.A, De Goes M.F,.“Monomer conversion of preheated composite. J. Dent. Res., 84, 663$667,2005$.

25- Lovell LG., Newman SM., Bowman CN. The effect of light intensity, temperature and comonomer composition on the polymerization behavior of dimethacrylate dental resin. J. Dent. Res. 78, 1469-1476, 1999.

26- Cansu Atalay, A. Ruya Yazici , Gul Ozgunaltay. Bond strength of Bulk-fill resin composite repairs: Effect of different surface treatment protocols in vitro. J of Ad Sci and Tech. Vol. 32 (9), 2018.

27- Brosh T., Pilo R., Bichacho N., Blutstein R. Effect of combinations of surface treatments and bonding agents on the bond strength of repaired composites. J. Prosthet. Dent.; 77:122; 1997.

28- Bonstein T., Garlapo D., Donarummo J., Jr., Bush P.J. Evaluation of varied repair protocols applied to aged composite resin. J. Adhes. Dent. 7:41-49; 2005.

29- Shahdad S.A., Kennedy J.G. Bond strength of repaired anterior composite resins: An in vitro study. J. Dent. 26:685694; 1998.

30- Costa T.R., Ferreira S.Q., Klein-Junior C.A., Loguercio A.D., Reis A. Durability of surface treatments and intermediate agents used for repair of a polished composite. Oper. Dent. 35:231-237; 2010.

31- Ghazaleh Ahmadizenous, Behnaz Esmaelli, Amica Taghavael, Zahra Jamali, Toloo Jafari, Farshid Amri Daneshavor, Soraya Khafri. Effect of different surface treatments on the shear bond strength of nano-filled composite repairs. Vol 10 (1) 2016 
32- Susannoa Dall Oca,Federica Papacchini, Ivanna Radovic, Antonella Polimen, Marco Ferrari. Repair protocol of a laboratory processed nano-hybrid resin composite. J. Oral Science. Vol. 50 (4), 403-412, 2008.

33- Renata Martos, virltoria Hegedüs, Melinda Szaloki, Igor R Blum, Christopher Lynch, Csaba Hegedüs. A randomised controlled study on the effects of different surface treatments and adhesive self-etch functional monomers on the immediate repair bond strength and integrity of the repaired resin composite interface. J of Dent. 04; 012; 2019.

34- Fawzy AS, El-Askary FS, Amer MA. Effect of surface treatments on the tensile bond strength of repaired wateraged anterior restorative micro-fine hybrid resin composite. J Dent. 36:969-976; 2008.

35- Rinastiti M, Ozcan M, Siswomihardjo W, Busscher HJ. Immediate repair bond strengths of microhybrid, nanohybrid and nano-filled composites after different surface treatments. J Dent 2010; 3:29-38, 2009

36- Finer Y, Santerre JP. Salivary esterase activity and its association with the biodegradation of dental composites. $\mathrm{J}$ Dent Res. 83:22-6; 2004.
37- Brendeke J, Qzcan M. Effect of physicochemical aging conditions of the composite-composite repair bond strength. J Adhes Dent. 9:399-406; 2007.

38- Farid elaskary, Richard van Noort, Ahmed el Banna. Immediate Vs delayed repair bond strength of a nano-hybrid resin composite. J. of Adhes. Dent. 14 (3): 265-74, 2012.

39- Nazire Nurdan Cakir, Sezer Demirbuga, Muhammet Karadas. Bonding performance of universal adhesives on composite repairs, with or without silane application. J of Cons Dent. 21 (3): 263-268; 2018

40- Cutris AR., Shortall AC., Marquis PM., Palin WM. Water uptake and strength characteristics of a nanofilled resinbased composite. J. Dent. 36: 186-193; 2008

41- Mutlu Özcan, Pedro Henrique Corazza, Susana Maria Salazar, Silvia Helna Barbosa, Marco Antonio Bottino. Repair bond strength of micro-hyhbrid, nano-hybrid and nanofilled resin composites: Effect of substrate resin type, surface conditioning and aging. Clin. Oral. Invest., 17: 1751-1758, 2013. 